\title{
Reduction and Gasification Characteristics of A Unique Iron Ore/ carbon Composite Prepared from Robe River and A Coal Tar Vacuum Residue
}

\author{
Kouichi MIURA, ${ }^{1) *}$ Jingchong YAN, ${ }^{1)}$ Hideaki OHGAKI, ${ }^{1)}$ Ryuichi ASHIDA ${ }^{2)}$ and Kazuhira ICHIKAWA ${ }^{3)}$ \\ 1) Institute of Advanced Energy, Kyoto University, Gokasho, Uji, 611-0011 Japan. \\ 2) Department of Chemical Engineering, Kyoto University, Nishikyo-ku, Kyoto, 615-8510 Japan. \\ 3) Steel Research Laboratory, JFE Steel Corporation, 1 Kawasaki-cho, Chuo-ku, Chiba, 260-0835 Japan.
}

(Received on March 29, 2019; accepted on June 11, 2019; J-STAGE Advance published date: August 30, 2019)

\begin{abstract}
We have prepared a unique iron ore/carbon composites (IOC) from a low grade iron ore called Robe River and a thermoplastic carbonaceous material. When Robe River which contains iron as goethite, $\mathrm{FeOOH}$, is heated up to 250 to $300^{\circ} \mathrm{C}$, the $\mathrm{OH}$ groups are removed as $\mathrm{H}_{2} \mathrm{O}$, leaving flat pore spaces of $0.8 \mathrm{~nm}$ wide between $2.0 \mathrm{~nm}$ thick $\mathrm{Fe}_{2} \mathrm{O}_{3}$ layers. The pore spaces are, however, closed over $300^{\circ} \mathrm{C}$ by the sintering of the $\mathrm{Fe}_{2} \mathrm{O}_{3}$ layers. The idea proposed is to insert the thermoplastic carbonaceous material into the pore space of $0.8 \mathrm{~nm}$ wide while the pore spaces are opened and to carbonize it to form carbon in the pore space below $500^{\circ} \mathrm{C}$. The iron oxide in the $\mathrm{IOC}$ thus prepared is reduced very rapidly in inert atmosphere and the carbon retained in the pore space is gasified by $\mathrm{CO}_{2}$ very rapidly also. In this work the reaction characteristics of the unique iron ore/carbon composite prepared from Rove River and a coal tar vacuum residue, CTVR, were examined for its direct reduction, indirect reduction in a $\mathrm{H}_{2}$ atmosphere, and coke gasification in a $\mathrm{CO}_{2}$ atmosphere from the viewpoints of reaction enthalpies and rate parameters. The examinations clarified that the carbonaceous material retained as coke in the pore space of iron ore are very reactive and show reaction characteristics different from bulk carbon.
\end{abstract}

KEY WORDS: iron ore/carbon composite; rapid reduction of iron ore; low grade iron ore; goethite; enthalpy of reduction; rapid gasification of carbon.

\section{Introduction}

In recent years a raw material forming fine iron ore particles and carbon material as briquette or pellet was proposed as a new feedstock of blast furnace. ${ }^{1-5)}$ We call this new raw material "iron ore/carbon composite (IOC)" in this paper. IOC has been developed with several purposes such as effective utilization of fine iron ore, a coke alternative with high gasification rate of carbon to $\mathrm{CO}_{2}$, and enhancement of direct reduction reaction. It is believed that the gasification of carbon in the IOC is enhanced by the catalytic effect of iron ore particles, and the direct reduction is enhanced by the intimate contact of iron ore particles and carbon material in the IOC. The rates of the direct reactions for several IOC samples were examined by Iguchi et al. ${ }^{6,7)}$ The reaction rates were, however, rather small below $1000^{\circ} \mathrm{C}$. Kasai et al. ${ }^{8)}$ examined the reactions involved in the reduction of IOC sample by preparing IOC samples through mixed-grinding of carbonaceous material and iron oxide. They found that the reduction rate was increased with the increase of milling time. They presumed that the increase

\footnotetext{
* Corresponding author: E-mail: miura.kouichi.q42@kyoto-u.jp DOI: https://doi.org/10.2355/isijinternational.ISIJINT-2019-048
}

was brought about by the catalytic effect and/or change of the rate limiting step from the gasification of carbon to the direct reduction reactions. However, the discussion was all for the reactions around $1000^{\circ} \mathrm{C}$ or over. Kashiwaya et al. examined the effect of the mixed-grinding on the reduction rate in more detail using hematite-graphite mixture in a series of works. ${ }^{9-12)}$ They have found that the milling in an Ar atmosphere for $1000 \mathrm{~h}$ decreased the reduction reaction peak temperature to as low as $700^{\circ} \mathrm{C}$. This dramatic effect was realized by the changes in not only the particle size but in the crystalline sizes of both iron ore and carbon during the milling, enhancing the direct reactions between solid iron oxide and carbon. This is interesting finding, but $1000 \mathrm{~h}$ milling will not be realistic for practical application. The occurrence of the direct reactions at around $700^{\circ} \mathrm{C}$ was also confirmed by in-situ TEM observation between a wuestite and carbon deposited on it. ${ }^{13)}$

We have reported that nano-sized $\mathrm{Fe}_{2} \mathrm{O}_{3}$ particles wrapped by a thermoplastic carbon material are reduced to $\mathrm{Fe}$ in several min at as low as $650^{\circ} \mathrm{C}$ in a $\mathrm{N}_{2}$ atmosphere, and that the plastic carbon surrounding the $\mathrm{Fe}_{2} \mathrm{O}_{3}$ particles is gasified completely in several min at as low as $700^{\circ} \mathrm{C}$ in a $\mathrm{CO}_{2}$ atmosphere. ${ }^{14)}$ It was found that the dramatic enhancement of the both reaction rates was realized by the enhancement of the 
direct reduction reaction. To realize this concept practically, we have prepared a unique iron ore/carbon composite (IOC) from a low grade iron ore, Robe River, and thermoplastic carbonaceous material. ${ }^{15}$ ) When Robe River is heated over $250^{\circ} \mathrm{C}$, dehydration reaction takes place and slit like pores of $0.8 \mathrm{~nm}$ width are formed between the layered $\mathrm{Fe}_{2} \mathrm{O}_{3}$ of $2.0 \mathrm{~nm}$ width. ${ }^{16)}$ The plastic carbon was inserted into the pores just by heating the mixture of Robe River and the plastic carbonaceous material. When the mixture is heated up to $500^{\circ} \mathrm{C}$ to prepare IOC, the carbonaceous material is pyrolyzed to produce light oil leaving the heavy fraction as coke within the nano-sized pores. ${ }^{17)}$ Robe River transformed to $\mathrm{Fe}_{3} \mathrm{O}_{4}$ in the IOC is reduced to Fe by solid-solid reaction between the layered $\mathrm{Fe}_{3} \mathrm{O}_{4}$ and the layered coke in several min at less than $900^{\circ} \mathrm{C}$. It was also found that the coke in the IOC is gasified very rapidly in both $\mathrm{CO}_{2}$ and $\mathrm{H}_{2} \mathrm{O}$ atmospheres by the catalytic effect of the layered $\mathrm{Fe}_{3} \mathrm{O}_{4}$. Thus the proposed IOC is expected to be a new and unique raw material for iron making.

It was judged that both the rapid reduction of iron ore and the rapid gasification of coke are realized by intimate contact of iron ore and coke with large interfacial area. It is well expected that the nano-sized coke retained in the pore space in the IOC will show reaction characteristics different from those of bulk carbon. It is also interesting to investigate how the iron ore in the IOC will be reduced by $\mathrm{H}_{2}$.

The purposes of this work are to examine the reaction characteristics of the IOC to direct reduction, indirect reduction in a $\mathrm{H}_{2}$ atmosphere, and coke gasification in a $\mathrm{CO}_{2}$ atmosphere from the viewpoints of reaction enthalpies and rate parameters. The IOC sample used for these purposes was prepared from Robe River and a coal tar vacuum residue. To estimate the reaction enthalpies, a TG-DSC analyzer which can simultaneously measure weight change and heat generation rate was used. A methodology to extract the heat generation rate coming from the reactions was developed for this purpose. To obtain the rate parameters, the weight change curves measured at three different heating rates were analyzed by the so called isoconversion method.

\section{Experimental}

\subsection{IOC Sample Used}

Tables 1 and 2 respectively show the properties of the iron ore, Robe River (abbreviated to RR), and a coal tar vacuum residue (CTVR) used as the carbonaceous material. Most of $\mathrm{Fe}$ in Robe River exists as goethite, judging from

Table 1. Analysis of Robe River.

\begin{tabular}{cccccccc}
\hline \multirow{2}{*}{$\mathrm{D}_{\mathrm{p}}[\mu \mathrm{m}]$} & \multicolumn{7}{c}{ Composition $[\mathrm{wt} \%]$} \\
& Total.Fe & $\mathrm{FeO}$ & $\mathrm{SiO}_{2}$ & $\mathrm{Al}_{2} \mathrm{O}_{3}$ & $\mathrm{CaO}$ & $\mathrm{MgO}$ & $\mathrm{LOI}^{*}$ \\
\hline$<150$ & 55.82 & 0.11 & 5.85 & 2.73 & 0.3 & 0.23 & 10.63 \\
\hline
\end{tabular}

Table 2. Analysis of coal tar VR.

\begin{tabular}{ccccccc}
\hline \multicolumn{3}{c}{ Ultimate Analysis $[\mathrm{wt} \%$, d.a.f.] } & \multicolumn{3}{c}{ Proximate Analysis $[\mathrm{wt} \%$, d.b.] } \\
\hline $\mathrm{C}$ & $\mathrm{H}$ & $\mathrm{N}$ & $\mathrm{S}+\mathrm{O}$ (Diff) & $\mathrm{VM}$ & $\mathrm{FC}$ & Ash \\
\hline 90.7 & 3.1 & 1.5 & 4.8 & 49.6 & 51.3 & 0.05 \\
\hline
\end{tabular}

the LOI (ignition loss) value. Robe River ground into less than $150 \mu \mathrm{m}$ and CTVR powder was mixed at 3 to 1 mass ratio and the mixture was formed to make pellet of $14 \mathrm{~mm}^{\varphi}$ and 8 to $10 \mathrm{~mm}$ high under the load of $40 \mathrm{MPa}$. The pellet was heated to $500^{\circ} \mathrm{C}$ in a nitrogen atmosphere to prepare the iron ore/carbon composite (IOC). The IOC ground into less than $150 \mu \mathrm{m}$ was served to experiments. Figure 1 shows the XRD profile of the IOC obtained using an X-ray diffractometer (RIGAKU Co. Ltd, Ultima IV). It shows distinct peaks attributed to only $\mathrm{Fe}_{3} \mathrm{O}_{4}$, indicating that the carbon inside the IOC, which we call coke in this paper, exists as amorphous carbon. The composition of the IOC by assuming that iron exists solely as $\mathrm{Fe}_{3} \mathrm{O}_{4}$ is given in Table 3. The carbon to Fe molar ratio $(\mathrm{C} / \mathrm{Fe})$ estimated is 2.21 which is larger than the stoichiometric value of the direct reduction reaction given by Reaction (1) given below (=1.33).

To examine the properties of coke inside the IOC, the IOC was treated by HF to recover the coke by dissolving the $\mathrm{Fe}_{3} \mathrm{O}_{4}$. The XRD profile and TEM photos, obtained by a TEM spectrometer (JEOL, JEM-1010), of the coke are respectively shown in Figs. 1 and 2. The TEM photos show that the recovered coke (Dem coke) looks like small thin layered graphene like carbons. Reflecting this structure, the XRD of the Dem coke shows rather broad peaks attributed to graphite. Figure 3 shows the $\mathrm{N}_{2}$ adsorption/desorption isotherms of the Dem coke, the Robe River heated to $315^{\circ} \mathrm{C}$ in a nitrogen atmosphere, and the IOC measured using a nitrogen adsorption apparatus (BEL JAPAN Inc., BELSORP-mini,). The Robe River heated to $315^{\circ} \mathrm{C}$ had as large as $75 \mathrm{~m}^{2} / \mathrm{g}$ of BET surface area which comes from the slit shaped pores formed by the dehydration of the Robe River as stated in Introduction. On the other hand, the IOC showed no appreciable $\mathrm{N}_{2}$ adsorption, which indicates that

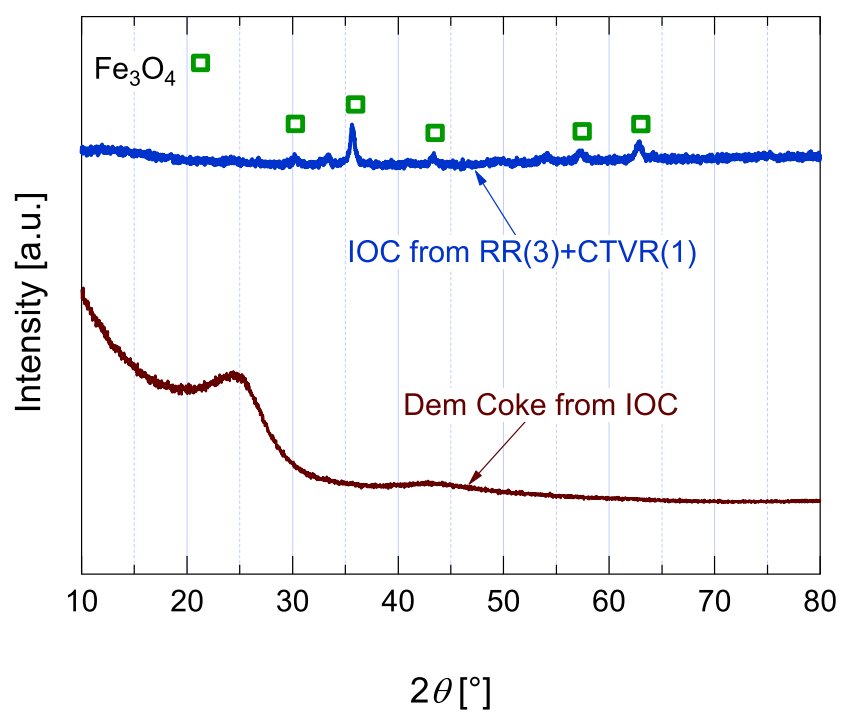

Fig. 1. XRD profiles of the samples used. (Online version in color.)

Table 3. Composition of the IOC used.

\begin{tabular}{cccccc}
\hline & \multicolumn{3}{c}{ Composition $[\mathrm{kg} / \mathrm{kg}$-IOC $]$} & & $\mathrm{C} / \mathrm{Fe}$ \\
& $\mathrm{Fe}_{3} \mathrm{O}_{4}$ & $\mathrm{As} \mathrm{Fe}$ & $\mathrm{C}$ & Others & {$[\mathrm{mol} / \mathrm{mol}]$} \\
\hline $\mathrm{IOC}\left(500^{\circ} \mathrm{C}\right)$ & 0.681 & 0.493 & 0.235 & 0.084 & 2.21 \\
\hline
\end{tabular}



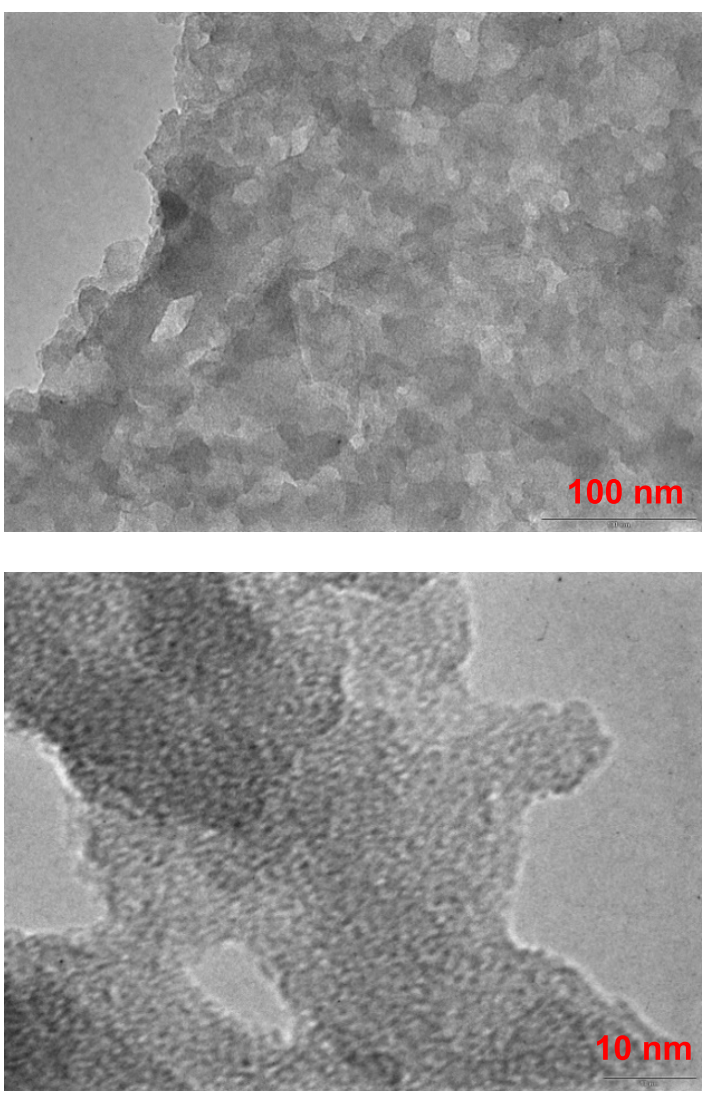

Fig. 2. TEM images of the demineralize coke. (Online version in color.)

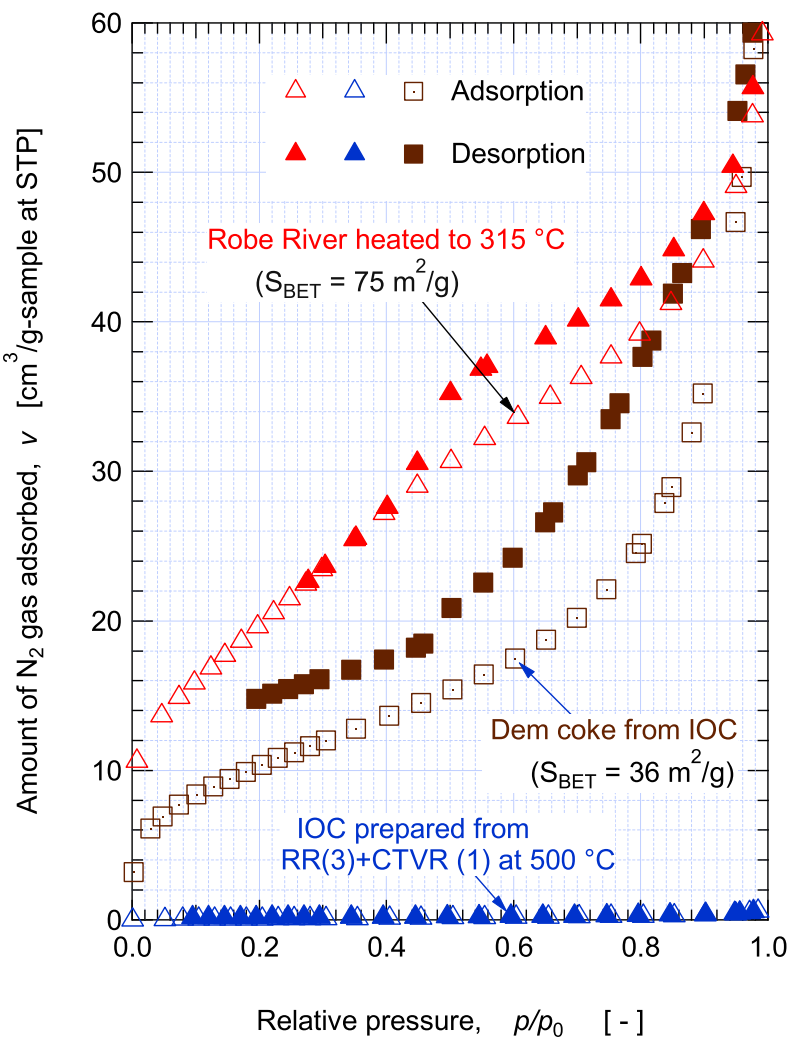

Fig. 3. Adsorption/desorption isotherms of the samples used. (Online version in color.)

the entire pore space of the Robe River that is formed by the hydration is occupied by the coke. The coke and the $\mathrm{Fe}_{3} \mathrm{O}_{4}$ surface are so intimately contacting that nitrogen cannot penetrate the pores. Very interestingly, however, the $\mathrm{N}_{2}$ adsorption/desorption isotherm of the Dem coke showed big hysteresis and the BET surface area calculated from the adsorption isotherm was as large as $36 \mathrm{~m}^{2} / \mathrm{g}$. This shows that the coke is disintegrated when $\mathrm{Fe}_{3} \mathrm{O}_{4}$ was removed from IOC by the HF treatment and stacking structure of small thin layered graphene like carbons is formed as stated above. The IOC and the Dem coke having such unique properties were used as starting materials in this work.

\subsection{Apparatus and Procedure to Estimate Reaction Enthalpies}

One of the purposes of this work is to measure the reaction enthalpies of the direct reduction, indirect reduction by $\mathrm{H}_{2}$, and the gasification of coke by $\mathrm{CO}_{2}$. To do so, we intended to use a TG-DSC analyzer (NETZSCH, STA449 F3) by which we can measure the weight change and the heat generation rate simultaneously using a same sample. When the weight change is related to the degree of reaction, the reaction enthalpy is easily estimated. DSC is very sensitive to detect the sensible heats of sample and sample holder and heat generation/absorption by phase change of sample. Since we want to extract only the heat generation/absorption signal coming from the reaction in focus, we must subtract the signal coming from sensible heats of sample and sample holder from the total signal. In strict sense it is almost impossible to do so, because the amount of sample changes with the progress of reaction and the sensible heat of sample changes accordingly. Then some approximate treatment is necessary to extract the heat generation/absorption signal coming from the reaction in focus. For the TG measurement using the TG-DSC, buoyancy correction is essential for the TG signal.

First, the weight changes of IOC by the three reactions in focus were examined. The overall stoichiometry of the three reactions in focus are respectively represented by

Direct reduction of $\mathrm{Fe}_{3} \mathrm{O}_{4}: \mathrm{Fe}_{3} \mathrm{O}_{4}+4 \mathrm{C} \rightarrow 3 \mathrm{Fe}+4 \mathrm{CO}$

Indirect reduction of $\mathrm{Fe}_{3} \mathrm{O}_{4}$ by $\mathrm{H}_{2}$ :

$$
\mathrm{Fe}_{3} \mathrm{O}_{4}+4 \mathrm{H}_{2} \rightarrow 3 \mathrm{Fe}+4 \mathrm{H}_{2} \mathrm{O}
$$

$$
\text { Gasification of coke by } \mathrm{CO}_{2}: \mathrm{C}+\mathrm{CO}_{2} \rightarrow 2 \mathrm{CO}
$$

The relative weight of the IOC after completion of the three reactions can be calculated by following the reaction stoichiometry with the aid of the composition given in Table 3 as 0.671 for the direct reduction, 0.812 for the indirect reduction, and 0.765 for the gasification. These calculations indicate that the weight change of the IOC sample is rather small. This suggests that the heat absorption coming from sensible heats of sample and sample holder may be approximately estimated by performing the exactly same measurement using the IOC sample just being reacted to the completion of reaction. The validity of this methodology was examined using the following pyrolysis reaction:

$$
\mathrm{CaCO}_{3}(\mathrm{~s}) \rightarrow \mathrm{CaO}(\mathrm{s})+\mathrm{CO}_{2}(\mathrm{~g})
$$

Figure 4 shows the result of simultaneous TG and DSC measurements using a reagent grade $\mathrm{CaCO}_{3}$. First, about $14 \mathrm{mg}$ of powdered $\mathrm{CaCO}_{3}$ was heated in a $\mathrm{N}_{2}$ stream flow- 


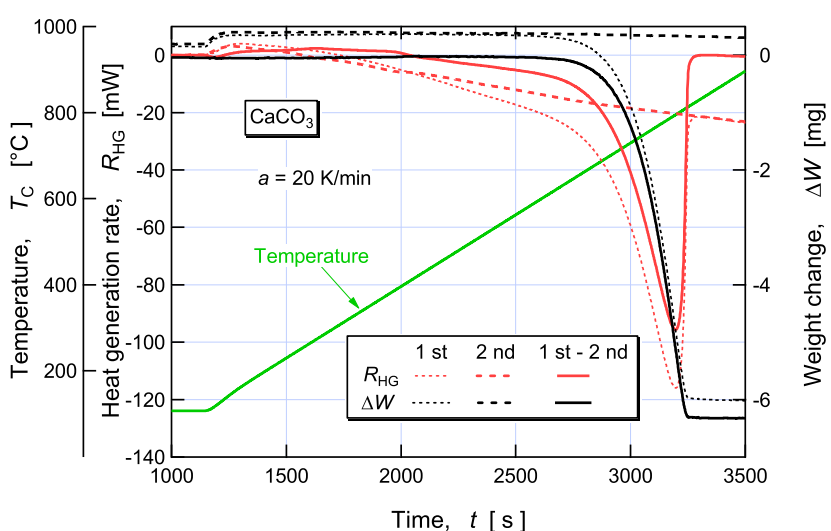

Fig. 4. TG-DSC profiles for the thermal decomposition of $\mathrm{CaCO}_{3}$. (Online version in color.)

ing at $100 \mathrm{~mL} / \mathrm{min}$ using the TG-DSC analyzer by following the temperature profile shown by the green solid line. The TG and DSC profiles obtained are respectively shown by the thin dot lines of black and red (1st measurement). The DSC profile showed a large endothermic peak having a maximum at around $800^{\circ} \mathrm{C}$ in parallel to the sharp decrease of the sample weight, but it deviated from the baseline when the reaction was completed. Next, the remaining $\mathrm{CaO}$ was cooled down to room temperature in the TG-DSC analyzer in the $\mathrm{N}_{2}$ stream, and it was heated again by following the exactly same temperature profile in the $\mathrm{N}_{2}$ stream to obtain the 2nd TG and DSC profiles, which are respectively shown by the thick broken lines of black and red. The TG profile of the 2nd measurement almost exactly followed that of the 1 st measurement up to over $600^{\circ} \mathrm{C}$, whereas the DSC signal of the 2nd measurement gradually decreased, which indicates gradual increase of endothermic rate, and finally almost exactly coincided with the DSC signal of the 1st measurement. Then the 2nd TG and DSC signals were subtracted from the corresponding 1st signals to obtain corrected signals shown respectively by the thick solid lines of black and red ( $2 \mathrm{nd}-1 \mathrm{st})$. The corrected TG signal showed smooth and rapid weight decrease over $600^{\circ} \mathrm{C}$ and the completion of the reaction at around $800^{\circ} \mathrm{C}$. The final weight was almost exactly same as the weight expected from the reaction stoichiometry, indicating that the buoyancy correction could be done successfully. The corrected DSC signal showed large endothermic peak in parallel to the weight decrease and returned to the baseline at the completion of reaction, suggesting the validity of the methodology. The corrected DSC signal was integrated against time to obtain the accumulated amount of heat generated, which was then plotted against the weight decrease as shown in Fig. 5. The slope at a specified point gives the local value of the reaction enthalpy in the unit of $\mathrm{kJ} / \mathrm{kg}$. Since the weight change is plotted to the direction of weight decrease, namely to the direction of reaction progress, the downward-sloping curve shows endothermic reaction. The slopes corresponding to the thermodynamic reaction enthalpies at three temperatures of 700,750 , and $800^{\circ} \mathrm{C}$ are shown by red broken lines. The slopes of the measured relationship between the accumulated amount of heat and the weight decrease were so close to those of the broken lines. These examinations showed the validity of the proposed methodology to extract the DSC signal coming solely from reaction.

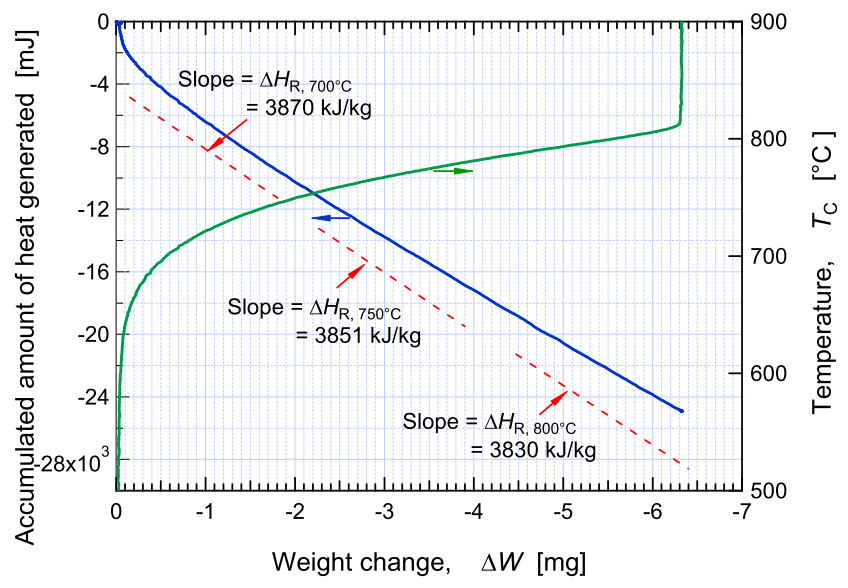

Fig. 5. Relationship between the accumulated amount of heat generated and weight change for the thermal decomposition of $\mathrm{CaCO}_{3}$. (Online version in color.)

Based on the preliminary experiment, the 1 st experiments to obtain the reaction enthalpies of the three reactions in focus were performed as follows:

(a) Direct reduction of $\mathrm{Fe}_{3} \mathrm{O}_{4}$ in the IOC: 15 to $30 \mathrm{mg}$ of the IOC sample was heated from $500^{\circ} \mathrm{C}$ at the rate of 5 , 10 , or $20 \mathrm{~K} / \mathrm{min}$ in a $\mathrm{N}_{2}$ stream flowing at $100 \mathrm{~mL} / \mathrm{min}$ using the TG-DSC analyzer. The product gas formed after $500^{\circ} \mathrm{C}$ was analyzed for $\mathrm{CO}, \mathrm{CO}_{2}$, and $\mathrm{H}_{2} \mathrm{O}$ in every one minute using a micro gas chromatograph (GL Science, Micro GC CP 4900).

(b) Indirect reduction of $\mathrm{Fe}_{3} \mathrm{O}_{4}$ in the $\mathrm{IOC}$ by $\mathrm{H}_{2}$ : 15 to $30 \mathrm{mg}$ of the IOC sample was heated at the rate of 5, 10, or $20 \mathrm{~K} / \mathrm{min}$ up to $900^{\circ} \mathrm{C}$ in a mixed gas stream of $10 \%$ $\mathrm{H}_{2}$ and $90 \% \mathrm{~N}_{2}\left(\mathrm{H}_{2}(10 \%) / \mathrm{N}_{2}\right)$ flowing at $100 \mathrm{~mL} / \mathrm{min}$ using the TG-DSC analyzer. For comparison purpose, an experiment using Robe River itself was also performed.

(c) Gasification of coke by $\mathrm{CO}_{2}$ : About $30 \mathrm{mg}$ of the IOC sample was heated at the rate of $10 \mathrm{~K} / \mathrm{min}$ up to $1000^{\circ} \mathrm{C}$ in a gas stream of $\mathrm{CO}_{2}$ flowing at $100 \mathrm{~mL} / \mathrm{min}$ using the TG-DSC analyzer.

For all the TG-DSC measurements, 2nd experiments were performed as were done for the pyrolysis of $\mathrm{CaCO}_{3}$, and the signals subtracting 2 nd signals from 1 st signals were used for estimating the reaction enthalpies. The effects of gas streams on the magnitude of DSC signals were also corrected. The relative sensitivities to the $\mathrm{N}_{2}$ stream were determined to be 1.15 for $\mathrm{CO}_{2}$ stream and 2.77 for the mixed gas stream of $10 \% \mathrm{H}_{2}$ and $90 \% \mathrm{~N}_{2}$ from preliminary experiments.

\subsection{Apparatus and Procedure to Estimate Rate Param- eters}

For (a) direct reduction and (b) indirect reduction by $\mathrm{H}_{2}$, the TG curves obtained using the TG-DSC analyzer at the heating rate of 5,10 , or $20 \mathrm{~K} / \mathrm{min}$ were used. For (c) coke gasification, about $30 \mathrm{mg}$ of the IOC sample was heated at the rate of 5,10 , or $20 \mathrm{~K} / \mathrm{min}$ up to $1100^{\circ} \mathrm{C}$ in a gas stream of $\mathrm{CO}_{2}$ flowing at $100 \mathrm{~mL} / \mathrm{min}$ using a $\mathrm{TG}$ analyzer (Shimadzu, TG-50H). The TG curves were analyzed by the so called isoconversion method to obtain local activation energies. Several reaction models were tested to formulate the rate equations as described in detail below. 


\section{Results and Discussion}

\subsection{TG and DSC Signals Obtained by the Proposed Methodology}

Figures 6 to 8 respectively show the TG-DSC profiles measured at the heating rate of $10 \mathrm{~K} / \mathrm{min}$ for (a) direct reduction, (b) indirect reduction by $\mathrm{H}_{2}$, and (c) coke gasification. For all the measurements, the TG signals of 1st-2nd show smooth changes and the DSC signals returned to the baseline when the reactions were completed, suggesting the validity of the proposed methodology to get reliable

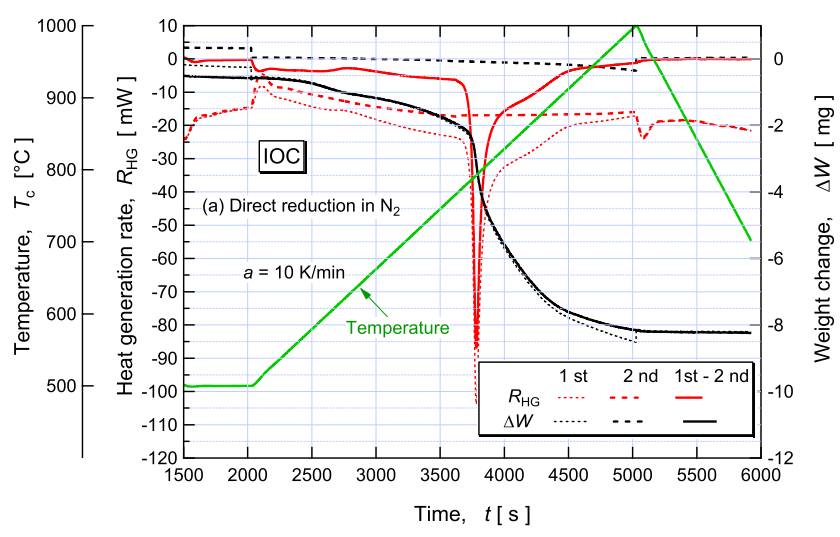

Fig. 6. TG-DSC profiles for the direct reaction experiment of IOC. (Online version in color.)

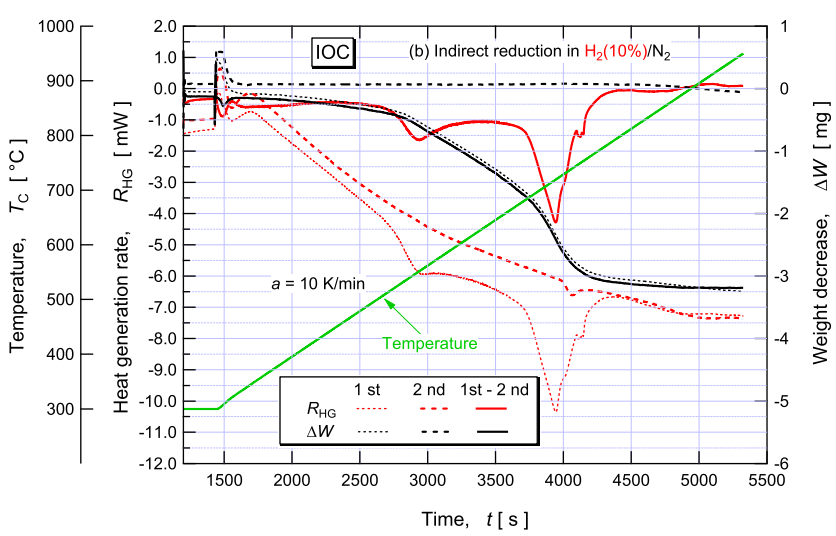

Fig. 7. TG-DSC profiles for the indirect reaction experiment of IOC in $\mathrm{H}_{2}(10 \%) / \mathrm{N}_{2}$ atmosphere. (Online version in color.)

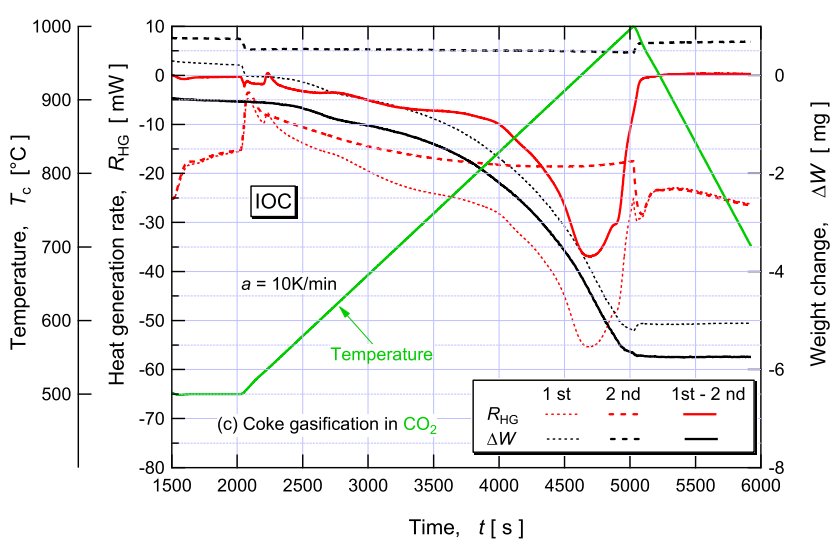

Fig. 8. TG-DSC profiles for the coke gasification experiment $\mathrm{CO}_{2}$ atmosphere. (Online version in color.)
TG and DSC signals. Figure 9 shows the TG-DSC profiles measured at the heating rate of $10 \mathrm{~K} / \mathrm{min}$ for the indirect reduction of Robe River itself by $\mathrm{H}_{2}$. Again the TG signal of 1 st -2 nd showed smooth changes and the DSC signal returned to the baseline when the reaction was completed.

\subsection{Weight Change and Degree of Reaction}

It is essential to know how the weight change is related to the degree of reaction to estimate the reaction enthalpy from the heat generation and the weight change. Then the normalized weight changes, $W / W_{0}$, and the heat generation rates per unit weight of sample, $\mathrm{d} Q / \mathrm{d} t$, calculated from Figs. 6 to 9 are shown against temperature in Fig. 10. Figure 11 shows the XRD profiles of the solid products remaining after the TG-DSC measurements with the XRD profile of the IOC. The iron species detected were $\mathrm{Fe}$ and $\mathrm{Fe}_{3} \mathrm{C}$ after the direct reduction experiment and only Fe for the IOC and Robe River after the indirect reduction experiments in the $\mathrm{H}_{2}(10 \%) / \mathrm{N}_{2}$ stream. The XRD spectrum for the IOC after the coke gasification experiment was almost same as that of the unreacted IOC and showed peaks coming from only $\mathrm{Fe}_{3} \mathrm{O}_{4}$. The final relative weight of the IOC after the indirect reduction experiment was 0.72 which was smaller than the value of 0.812 estimated by following the reaction stoichiometry of Reaction (2). On the other hand, the final relative weight of the Robe River after the indirect reduction experiment was 0.73 which was exactly equall to the value of 0.731 estimated by assuming that iron in Robe River exists solely as $\mathrm{Fe}_{2} \mathrm{O}_{3}$ at $300^{\circ} \mathrm{C}$ and $\mathrm{Fe}_{2} \mathrm{O}_{3}$ was completely reduced to iron. The final relative weight of the IOC after the coke gasification experiment was 0.76 which was almost equall to the value of 0.765 estimated by following the reaction stoichiometry of Reaction (3). These examinations show that the weight changes are proportional to the expected reaction degrees for the indirect reduction of Robe River and the gasification of coke in the IOC. The larger weight decrease than the expected reaction stoichiometry for the indirect reduction experiment indicates that the reaction of carbon in the IOC with $\mathrm{H}_{2}$ to produce hydrocarbon gases may occur at low temperature region, although the gas analysis could not detect distinct formation of hydrocarbon gases.

The relationship between the weight change and the degree of reaction was examined with the aid of gas formation behavior for the direct reduction experiment. Figure

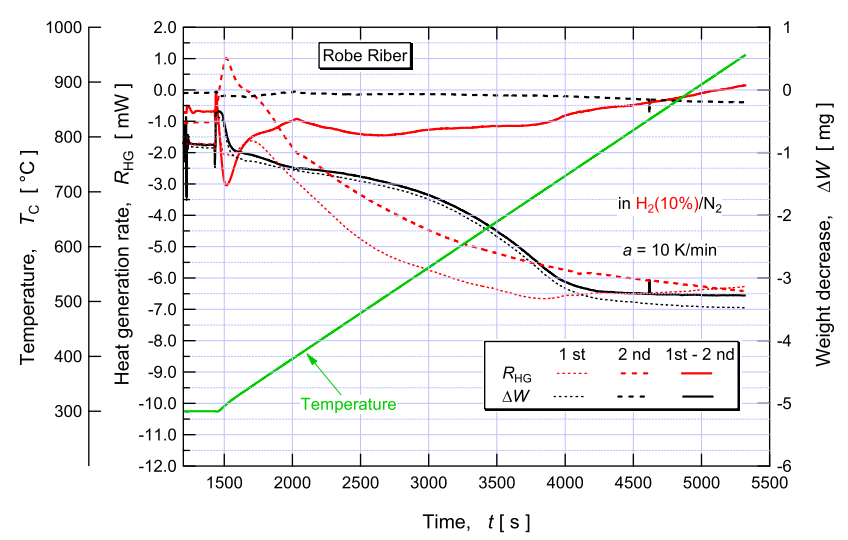

Fig. 9. TG-DSC profiles for the indirect reaction experiment of Robe River in $\mathrm{H}_{2}(10 \%) / \mathrm{N}_{2}$ atmosphere. (Online version in color.) 


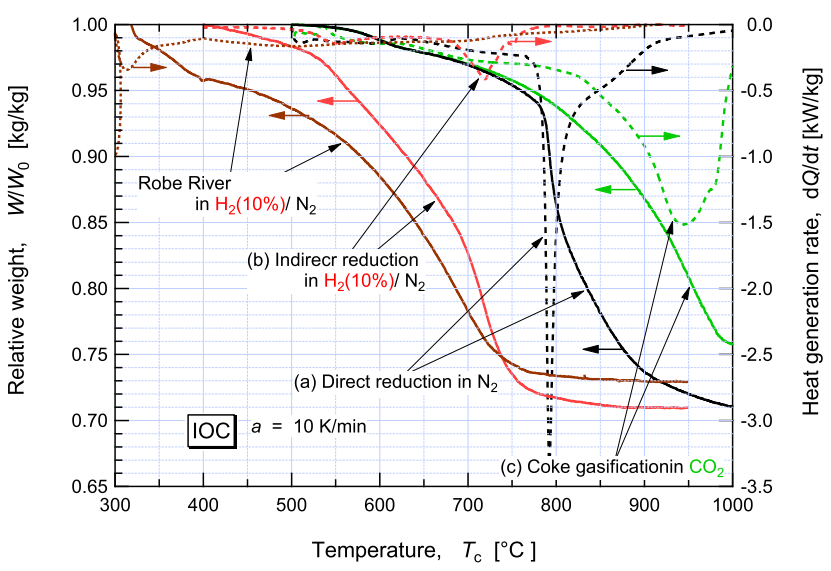

Fig. 10. Comparison of weight change and heat generation behaviors among the direct reduction, indirect reduction, and coke gasification of IOC and the direct reduction of Robe River. (Online version in color.)

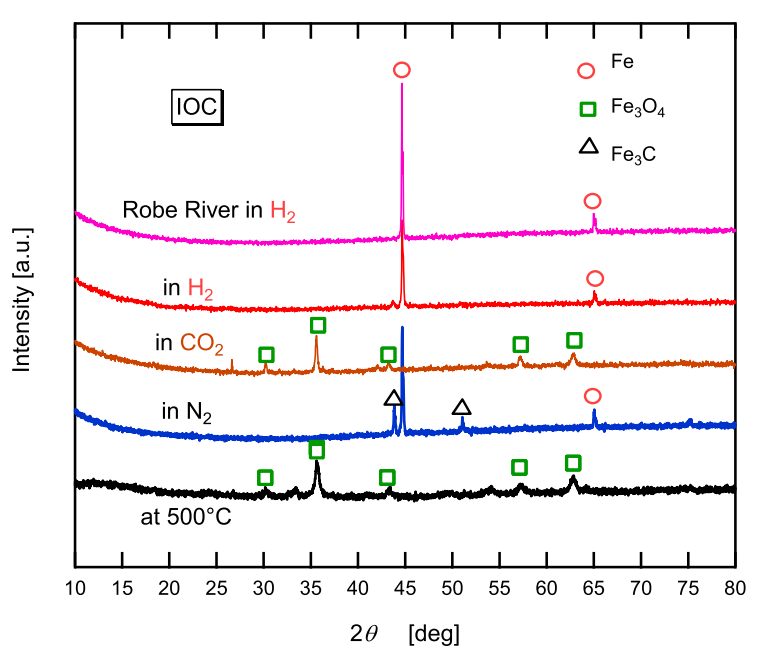

Fig. 11. XRD profiles of the IOC sample after the direct reduction, indirect reduction, and coke gasification and Robe River after the direct reduction. (Online version in color.)

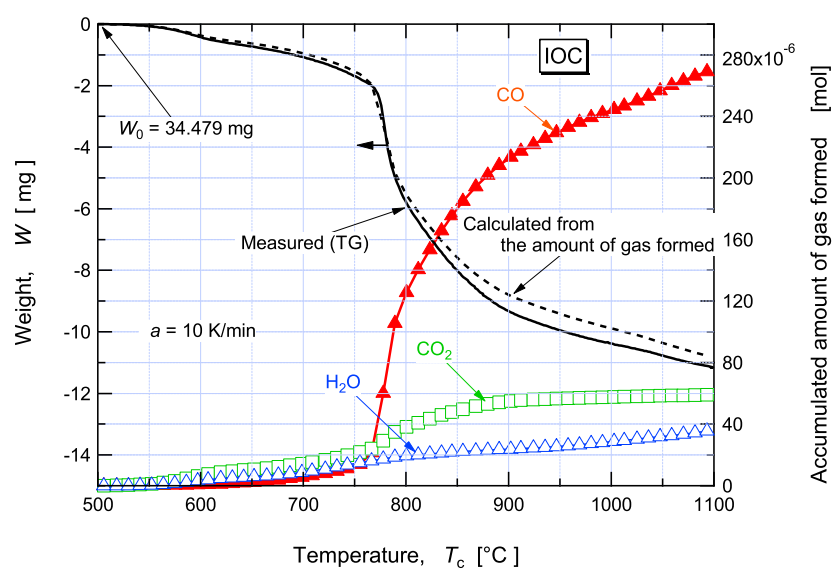

Fig. 12. TG-DSC profiles for the direct reaction experiment of IOC. (Online version in color.)

12 shows the accumulated amounts of gases formed against temperature for the direct reduction shown in Fig. 6. The reaction degree of the direct reduction was examined using Figs. 11 and 12. The measured weight change (solid line) showed good agreement with the weight change calculated

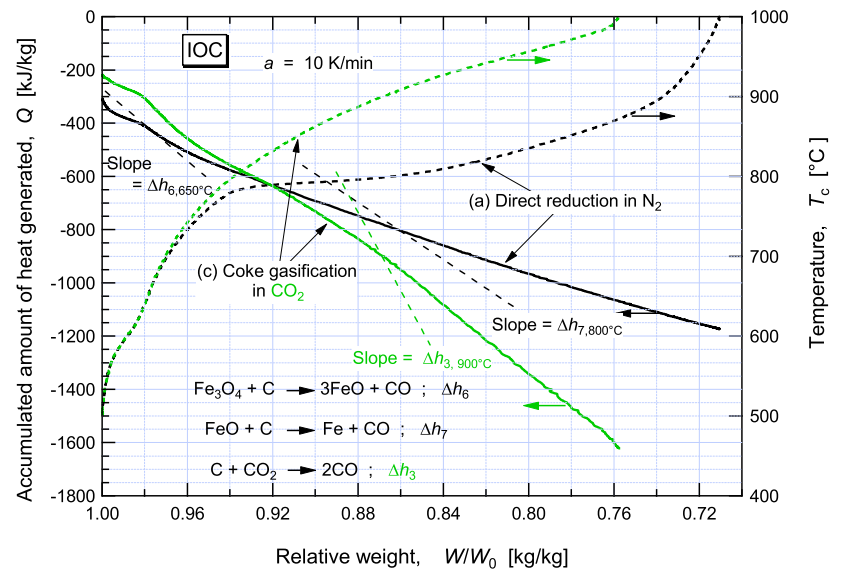

Fig. 13. Relationship between the accumulated amount of heat generated and weight change during the direct reduction and coke gasification of the IOC sample. (Online version in color.)

from the amount of three gases, $\mathrm{CO}, \mathrm{CO}_{2}$, and $\mathrm{H}_{2} \mathrm{O}$, formed (broken line), indicating that the measured weight change well represents the progress of the reduction. The amount of $\mathrm{O}$ existing as $\mathrm{Fe}_{3} \mathrm{O}_{4}$ in the IOC is calculated to be 0.188 $\mathrm{kg} / \mathrm{kg}$ from Table 3, whereas the amount of $\mathrm{O}$ evolved as $\mathrm{CO}$ and $\mathrm{CO}_{2}$ by $1100^{\circ} \mathrm{C}$ is $0.179 \mathrm{~kg} / \mathrm{kg}$, and the amount of $\mathrm{O}$ evolved as $\mathrm{CO}, \mathrm{CO}_{2}$, and $\mathrm{H}_{2} \mathrm{O}$ by $1100^{\circ} \mathrm{C}$ is $0.198 \mathrm{~kg} / \mathrm{kg}$. Assuming that the reduction of $\mathrm{Fe}_{3} \mathrm{O}_{4}$ in the IOC was completed by Reaction (1) and the indirect reduction, Reaction (5), by the CO produced by Reaction (1), the overall contributing ratio of the direct reduction, Reaction (1), to the reduction of $\mathrm{Fe}_{3} \mathrm{O}_{4}$ is calculated to be $0.85(=(270+58) \times$ $10^{-6} \mathrm{~mol} /\left((270+58+58) \times 10^{-6} \mathrm{~mol}\right)$.

$$
\mathrm{Fe}_{3} \mathrm{O}_{4}+4 \mathrm{CO} \rightarrow 3 \mathrm{Fe}+4 \mathrm{CO}_{2}
$$

These results indicates that $\mathrm{Fe}_{3} \mathrm{O}_{4}$ in the IOC was mostly reduced by the direct reduction reaction, and hence the weight decrease is approximately related to the degree of the direct reduction reaction.

\subsection{Estimation of Reaction Enthalpies from the TG- DSC Measurements}

The heat generation rates, $\mathrm{d} Q / \mathrm{d} t$, shown in Fig. 10 are integrated against time to obtain the accumulated amounts of heat generated, $Q$. Figure 13 plots $Q$ against $W / W_{0}$ for the direct reduction and the coke gasification as was done for the decomposition of $\mathrm{CaCO}_{3}$ in Fig. 5. Figure 14 shows corresponding plots for the indirect reduction of the IOC and Robe River. For every plot, the slope at a specified point gives the local value of the reaction enthalpy in the unit of $\mathrm{kJ} / \mathrm{kg}$. Since the weight change is plotted to the direction of weight decrease, namely to the direction of reaction progress, the downward-sloping curve shows endothermic reaction as stated above. The reduction experiments in $\mathrm{N}_{2}$ is judged to involve the following four reactions:

$$
\begin{gathered}
\mathrm{Fe}_{3} \mathrm{O}_{4}+\mathrm{C} \rightarrow 3 \mathrm{FeO}+\mathrm{CO} \\
\mathrm{FeO}+\mathrm{C} \rightarrow \mathrm{Fe}+\mathrm{CO} \ldots .
\end{gathered}
$$

$\mathrm{Fe}_{3} \mathrm{O}_{4}+\mathrm{CO} \rightarrow 3 \mathrm{FeO}+\mathrm{CO}_{2}$ 


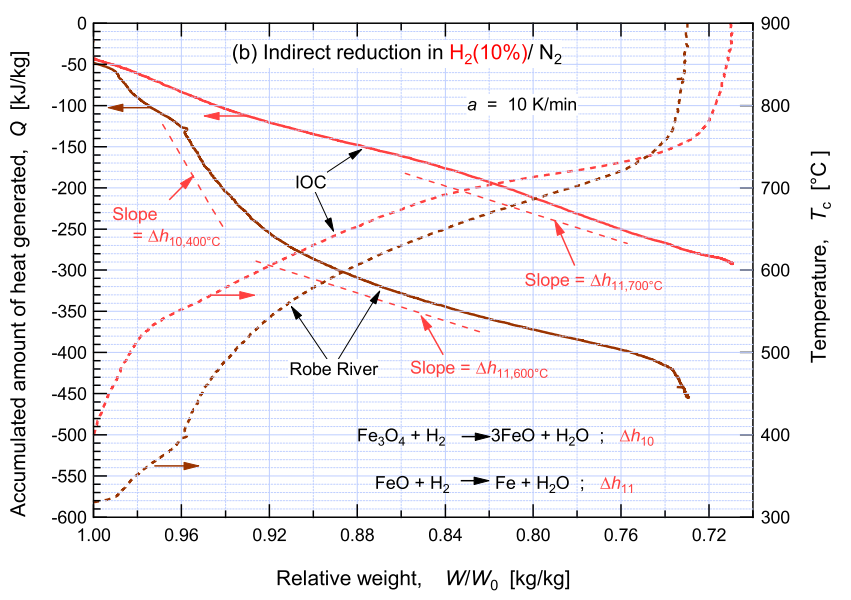

Fig. 14. Relationship between the accumulated amount of heat generated and weight change for the IOC sample and Robe River during the indirect reduction experiments. (Online version in color.)

$$
\mathrm{FeO}+\mathrm{CO} \rightarrow \mathrm{Fe}+\mathrm{CO}_{2}
$$

The indirect reduction of the IOC by $\mathrm{H}_{2}$ involves the following reactions:

$$
\begin{gathered}
\mathrm{Fe}_{3} \mathrm{O}_{4}+\mathrm{H}_{2} \rightarrow 3 \mathrm{FeO}+\mathrm{H}_{2} \mathrm{O} \\
\mathrm{FeO}+\mathrm{H}_{2} \rightarrow \mathrm{Fe}+\mathrm{H}_{2} \mathrm{O} \ldots . .
\end{gathered}
$$

Tables $\mathbf{4}$ to $\mathbf{1 0}$ show the thermodynamic reaction enthalpies of Reactions (6) to (11) and (3): $\Delta H_{\mathrm{R}}$ in the unit of $\mathrm{kJ} \cdot \mathrm{mol}^{-1}$ and $\Delta h_{\mathrm{R}}$ in the unit of $\mathrm{kJ}$ per $\mathrm{kg}$ of change of the IOC. The $\Delta h_{\mathrm{R}}$ values can be compared with the slopes in Figs. 13 and 14.

For the direct reduction experiments, the slopes of the $Q$ vs $W / W_{0}$ relationship were respectively 4950,2720 , and $2220 \mathrm{~kJ} / \mathrm{kg}$ at 650,800 , and $900^{\circ} \mathrm{C}$, whereas the $\Delta h_{\mathrm{R}}$ value of Reaction (6) was $6810 \mathrm{~kJ} / \mathrm{kg}$ at $650^{\circ} \mathrm{C}$ and the $\Delta h_{\mathrm{R}}$ values of Reaction (7) were respectively 5360 and $5400 \mathrm{~kJ} / \mathrm{kg}$ at 800 and $900^{\circ} \mathrm{C}$. The weight change in Fig. 12 shows that the reduction of $\mathrm{Fe}_{3} \mathrm{O}_{4}$ is occurring at $650^{\circ} \mathrm{C}$ but the dominant gaseous product is $\mathrm{CO}_{2}$. This means that $\mathrm{CO}$ formed by Reaction (6) is almost totally consumed by Reaction (8), which gives apparent $\Delta h_{\mathrm{R}}$ value of $4770 \mathrm{~kJ} / \mathrm{kg}$ $(=0.028 \times 6810 \mathrm{~kJ} / \mathrm{kg} /(0.028+0.016)+0.016 \times 1200 \mathrm{~kJ} /$ $\mathrm{kg} /(0.028+0.016))$. The value is rather close to the slope value of $4950 \mathrm{~kJ} / \mathrm{kg}$, indicating that the reaction enthalpy is well estimated. On the other hand, it is judged that Reaction (7) producing $\mathrm{CO}$ is prevailing at 800 to $900^{\circ} \mathrm{C}$, where the slope values are clearly much smaller than the $\Delta h_{\mathrm{R}}$ values of Reaction (7). The slope values are much smaller than the $\Delta h_{\mathrm{R}}$ values even if they are calculated by taking into account the contribution of Reaction (8). This shows that the measured reaction enthalpy for the direct reduction of the IOC over $700^{\circ} \mathrm{C}$ is less than half of the $\Delta h_{\mathrm{R}}$ value of Reaction (7).

For the coke gasification experiments, the slopes of the $Q$ vs $W / W_{0}$ relationship were respectively 3840,5720 , and $6220 \mathrm{~kJ} / \mathrm{kg}$ at 800,900 , and $950^{\circ} \mathrm{C}$, whereas the $\Delta h_{\mathrm{R}}$ values of Reaction (3) were respectively 14 190, 14 110, and $14070 \mathrm{~kJ} / \mathrm{kg}$ at 800,900 and $950^{\circ} \mathrm{C}$. Since just Reaction (3) is judged to occur in the $\mathrm{CO}_{2}$ atmosphere from Figs. 10 and 11 , the measured reaction enthalpies for the gasification of coke by $\mathrm{CO}_{2}$ are less than half of the thermodynamic reac-
Table 4. Reaction enthalpies of Reaction (6): $\mathrm{Fe}_{3} \mathrm{O}_{4}+\mathrm{C} \rightarrow 3 \mathrm{FeO}+$ CO.

\begin{tabular}{cccccccc}
\hline$T_{\mathrm{C}}\left[{ }^{\circ} \mathrm{C}\right]$ & 25 & 500 & 550 & 600 & 650 & 700 & 800 \\
\hline$\Delta H_{\mathrm{R}}\left[\mathrm{kJ} \cdot \mathrm{mol}^{-1}\right]$ & 214 & 204 & 200 & 196 & 191 & 185 & 173 \\
$\Delta h_{\mathrm{R}}\left[\mathrm{kJ} \cdot \mathrm{kg}^{\left.-\mathrm{CO}^{-1}\right]}\right.$ & 7650 & 7280 & 7140 & 6980 & 6810 & 6620 & 6180 \\
\hline
\end{tabular}

Table 5. Reaction enthalpies of Reaction (7): $\mathrm{FeO}+\mathrm{C} \rightarrow \mathrm{Fe}+$ CO.

\begin{tabular}{ccccccc}
\hline$T_{\mathrm{C}}\left[{ }^{\circ} \mathrm{C}\right]$ & 25 & 600 & 700 & 800 & 900 & 1000 \\
\hline$\Delta H_{\mathrm{R}}\left[\mathrm{kJ} \cdot \mathrm{mol}^{-1}\right]$ & 154 & 149 & 150 & 150 & 151 & 153 \\
$\Delta h_{\mathrm{R}}\left[\mathrm{kJ} \cdot \mathrm{kg}-\mathrm{CO}^{-1}\right]$ & 5490 & 5340 & 5340 & 5360 & 5400 & 5450 \\
\hline
\end{tabular}

Table 6. Reaction enthalpies of Reaction (8): $\mathrm{Fe}_{3} \mathrm{O}_{4}+\mathrm{CO} \rightarrow$ $3 \mathrm{FeO}+\mathrm{CO}_{2}$.

\begin{tabular}{cccccccc}
\hline$T_{\mathrm{C}}\left[{ }^{\circ} \mathrm{C}\right]$ & 25 & 500 & 550 & 600 & 650 & 700 & 800 \\
\hline$\Delta H_{\mathrm{R}}\left[\mathrm{kJ} \cdot \mathrm{mol}^{-1}\right]$ & 41.8 & 31.2 & 27.7 & 23.7 & 19.20 & 14.22 & 2.77 \\
$\Delta h_{\mathrm{R}}\left[\mathrm{kJ} \cdot \mathrm{kg}-\mathrm{O}^{-1}\right]$ & 2610 & 1950 & 1730 & 1480 & 1200 & 889 & 173.4 \\
\hline
\end{tabular}

Table 7. Reaction enthalpies of Reaction (9): $\mathrm{FeO}+\mathrm{CO} \rightarrow \mathrm{Fe}+$ $\mathrm{CO}_{2}$.

\begin{tabular}{ccccccc}
\hline$T_{\mathrm{C}}\left[{ }^{\circ} \mathrm{C}\right]$ & 25 & 600 & 700 & 800 & 900 & 1000 \\
\hline$\Delta H_{\mathrm{R}}\left[\mathrm{kJ} \cdot \mathrm{mol}^{-1}\right]$ & -18.58 & -22.4 & -21.4 & -20.0 & -18.18 & -15.82 \\
$\Delta h_{\mathrm{R}}\left[\mathrm{kJ} \cdot \mathrm{kg}^{-O}{ }^{-1}\right]$ & -1162 & -1398 & -1340 & -1253 & -1136 & -989 \\
\hline
\end{tabular}

Table 8. Reaction enthalpies of Reaction (10): $\mathrm{Fe}_{3} \mathrm{O}_{4}+\mathrm{H}_{2} \rightarrow$ $3 \mathrm{FeO}+\mathrm{H}_{2} \mathrm{O}$.

\begin{tabular}{ccccccc}
\hline$T_{\mathrm{C}}\left[{ }^{\circ} \mathrm{C}\right]$ & 25 & 400 & 450 & 500 & 550 & 600 \\
\hline$\Delta H_{\mathrm{R}}\left[\mathrm{kJ} \cdot \mathrm{mol}^{-1}\right]$ & 83.0 & 74.8 & 71.7 & 68.2 & 64.1 & 59.6 \\
$\Delta h_{\mathrm{R}}\left[\mathrm{kJ} \cdot \mathrm{kg}-\mathrm{O}^{-1}\right]$ & 5190 & 4670 & 4480 & 4260 & 4010 & 3730 \\
\hline
\end{tabular}

Table 9. Reaction enthalpies of Reaction (11): $\mathrm{FeO}+\mathrm{H}_{2} \rightarrow \mathrm{Fe}+$ $\mathrm{H}_{2} \mathrm{O}$.

\begin{tabular}{cccccccc}
\hline$T_{\mathrm{C}}\left[{ }^{\circ} \mathrm{C}\right]$ & 25 & 500 & 550 & 600 & 650 & 700 & 750 \\
\hline$\Delta H_{\mathrm{R}}\left[\mathrm{kJ} \cdot \mathrm{mol}^{-1}\right]$ & 22.6 & 14.2 & 13.8 & 13.6 & 13.4 & 13.5 & 13.6 \\
$\Delta h_{\mathrm{R}}\left[\mathrm{kJ} \cdot \mathrm{kg}-\mathrm{O}^{-1}\right]$ & 1410 & 885 & 862 & 848 & 841 & 841 & 850 \\
\hline
\end{tabular}

Table 10. Reaction enthalpies of Reaction (3): $\mathrm{C}+\mathrm{CO}_{2} \rightarrow 2 \mathrm{CO}$.

\begin{tabular}{ccccccc}
\hline$T_{\mathrm{C}}\left[{ }^{\circ} \mathrm{C}\right]$ & 25 & 600 & 700 & 800 & 900 & 1000 \\
\hline$\Delta H_{\mathrm{R}}\left[\mathrm{kJ} \cdot \mathrm{mol}^{-1}\right]$ & 172 & 172 & 171 & 170 & 169 & 168 \\
$\Delta h_{\mathrm{R}}\left[\mathrm{kJ} \cdot \mathrm{kg}^{\left.-\mathrm{C}^{-1}\right]}\right.$ & 14370 & 14320 & 14260 & 14190 & 14110 & 14030 \\
\hline
\end{tabular}

tion enthalpies.

For the indirect reduction experiments, the slopes of the $Q$ vs $W / W_{0}$ relationship for the Robe River were respectively 4640 and $860 \mathrm{~kJ} / \mathrm{kg}$ at 400 and $600^{\circ} \mathrm{C}$, whereas the $\Delta h_{\mathrm{R}}$ value of Reaction (10) is $4670 \mathrm{~kJ} / \mathrm{kg}$ at $400^{\circ} \mathrm{C}$ and the $\Delta h_{\mathrm{R}}$ value of Reaction (11) is $848 \mathrm{~kJ} / \mathrm{kg}$ at $600^{\circ} \mathrm{C}$. On the 
other hand, the slope of the $Q$ vs $W / W_{0}$ relationship for the IOC was almost constant over $650^{\circ} \mathrm{C}$ and was, for example, $810 \mathrm{~kJ} / \mathrm{kg}$ at $700^{\circ} \mathrm{C}$. Since it was expected that Reaction (11) is dominant at higher temperature region, the slope value is expected to correspond to the $\Delta h_{\mathrm{R}}$ value of Reaction (11). Actually the $\Delta h_{\mathrm{R}}$ value of Reaction (11) is $841 \mathrm{~kJ} / \mathrm{kg}$ at $700^{\circ} \mathrm{C}$ as given in Table 9. At lower temperature region the hydrogenation reaction of carbon in the IOC to produce hydrocarbon gas, which is exothermic reaction, is judged to occur. Then the slopes at lower temperature region come from Reaction (10) and the hydrogenation reaction, resulting in rather small slopes.

Summarizing the above discussion, the measured reaction enthalpies for the indirect reduction were rather close to those of thermodynamic reaction enthalpies when dominant reactions are identified, indicating not only the validity of the proposed methodology to estimate the reaction enthalpies but the little effect of the peculiar IOC structure to the indirect reduction reaction. On the other hand, the measured reaction enthalpies of both the direct reduction and the coke gasification were much smaller than the corresponding thermodynamic reaction enthalpies. This may come from the uniqueness of coke and intimate contact between the coke and the iron oxides. Some intermediate products which are different from bulk carbon and/or iron oxides may have been formed in the IOC.

\subsection{Determination of Activation Energies of the Three Reactions from TG Measurements}

The changing rate of conversion of solid reactant, $\mathrm{d} X / \mathrm{d} t$, is usually represented by the following equation for heterogeneous reactions such as pyrolysis, gas-solid reaction, etc.

$$
\frac{\mathrm{d} X}{\mathrm{~d} t}=k_{0} e^{-E / R T} f(X)
$$

where $t$ is the time, $k_{0}$ is the apparent frequency factor, $E$ is the activation energy, $T$ is the temperature, $R$ is the gas constant, and $f(X)$ represents some function of only solid conversion $X$. The apparent frequency factor $k_{0}$ is constant for pyrolysis but it is some function of the pressures of gaseous reactants for gas-solid reaction. However, it can be regarded as a constant when the pressures of gaseous reactants are kept constant as were for (b) indirect reduction and (c) coke gasification experiments of this work. For (a) direct reduction, both iron oxide and carbon are solid reactants, but the conversion of carbon is related to the conversion of iron ore. Then Eq. (12) is valid for (a) direct reduction also.

In this work the so called temperature programmed reaction technique that heats up solid samples from a low temperature $T_{0}$ under a constant heating rate $a$ was used to examine the three reactions, where weight change versus temperature relationships are utilized to extract the rate parameters of the reactions. The temperature of solid sample $T$ is related to time $t$ by

$$
T=T_{0}+a t
$$

Inserting Eq. (13) into Eq. (12) gives

$$
\frac{\mathrm{d} X}{\mathrm{~d} T}=\frac{k_{0}}{a} e^{-E / R T} f(X)
$$

This equation can be formally integrated to give $X$ versus $T$ relationship as

$$
g(X)=\int_{0}^{X} \frac{\mathrm{d} X}{f(X)}=\frac{k_{0}}{a} \int_{T_{0}}^{T} e^{-E / R T} \mathrm{~d} T \cong \frac{k_{0}}{a} \int_{0}^{T} e^{-E / R T} \mathrm{~d} T
$$

It is stressed here that integration is performed under the conditions of constant $k_{0}$ and $E$. Using the approximation proposed by Doyle, ${ }^{18)}$ Eq. (15) is represented as

$$
\begin{aligned}
g(X) & =\frac{k_{0}}{a} \int_{0}^{T} e^{-E / R T} \mathrm{~d} T=\frac{k_{0} E}{a R}\left(\frac{e^{-u}}{u}-\int_{u}^{\infty} \frac{e^{-u}}{u} \mathrm{~d} u\right) \\
& =\frac{k_{0} E}{a R} p(u) \cong k_{0} e^{-E / R T} \times \frac{R T^{2}}{a E}
\end{aligned}
$$

where $p(u)$ is set equal to $e^{-u / u^{2}}$. This approximation is known to be very accurate for $u=E / R T>15$.

When the form of $f(X)$ is unknown, a method which is called isoconversion method can be employed. Taking the logarithm of both sides, Eq. (16) can be rearranged to give

$$
\ln \left(\frac{a}{T^{2}}\right)=\ln \left(\frac{k_{0} R}{E}\right)-\ln g(X)-\frac{E}{R} \frac{1}{T}
$$

Since $g(X)$ is same at a selected $X$ value for different heating rates, the Arrhenius plots of $\ln \left(a / T^{2}\right)$ vs. $1 / T$ gives $E$ value at the conversion $X$. It should be stressed here that the Arrhenius plots at different $X$ levels should be in parallel if the reaction system consists of single reaction. If the Arrhenius plots are not in parallel, the reaction system cannot be represented by single reaction. This means that the analysis using Eq. (17) must be discarded, because Eq. (17) was obtained by integrating Eq. (14) by assuming constant $k_{0}$ and $E$ values. This analysis method is often called the Kissinger-Akahira-Sunose method. ${ }^{19)}$

Overcoming the weakness of the analysis method, Miura and Maki have shown that the Arrhenius plots of $\ln \left(a / T^{2}\right)$ vs. $1 / T$ gives local activation energies for multiple reactions also. ${ }^{20)}$ If the reaction in focus consists of $\mathrm{N}$ parallel reactions, the changing rate of the conversion of the i-th reaction, $\mathrm{d} X_{\mathrm{i}} / \mathrm{d} t$, can be written in analogy to Eq. (12) as

$$
\frac{\mathrm{d} X_{\mathrm{i}}}{\mathrm{d} t}=k_{0 \mathrm{i}} e^{-E_{\mathrm{i}} / R T} f_{\mathrm{i}}\left(X_{\mathrm{i}}\right)
$$

where the subscript $\mathrm{i}$ means the $\mathrm{i}$-th reaction and the overall conversion $X$ is given by $X=\sum_{\mathrm{i}=1}^{\mathrm{N}} X_{\mathrm{i} 0} X_{\mathrm{i}}$ using the fractional contribution of every reaction $X_{\mathrm{i} 0}$ defined by $\sum_{\mathrm{i}=1}^{\mathrm{N}} X_{\mathrm{i} 0}=1$. Equation (18) can be integrated to give

$$
g_{\mathrm{i}}\left(X_{\mathrm{i}}\right) \cong k_{0 \mathrm{i}} e^{-E_{\mathrm{i}} / R T} \times \frac{R T^{2}}{a E_{\mathrm{i}}}
$$

Taking logarithm of both sides, Eq. (19) can be rearranged to give

$$
\ln \left(\frac{a}{T^{2}}\right) \cong \ln \left(\frac{k_{0 \mathrm{i}} R}{E_{\mathrm{i}}}\right)-\ln g_{\mathrm{i}}\left(X_{\mathrm{i}}\right)-\frac{E_{\mathrm{i}}}{R} \frac{1}{T}
$$

Since it is a good approximation to assume that only the $\mathrm{i}$-th reaction is taking place at a certain conversion $X$, the Arrhenius plots of $\ln \left(a / T^{2}\right)$ vs. $1 / T$ at the conversion $X$ gives 
the activation energy of the $\mathrm{i}$-th reaction, $E_{\mathrm{i}}$.

The above discussion shows that the $W / W_{0}$ vs. $T$ relationships measured at 3 different heating rates are enough to estimate $E$ values covering whole reaction range. Figure 15 shows the $W / W_{0}$ vs. $T$ relationships for (a) direct

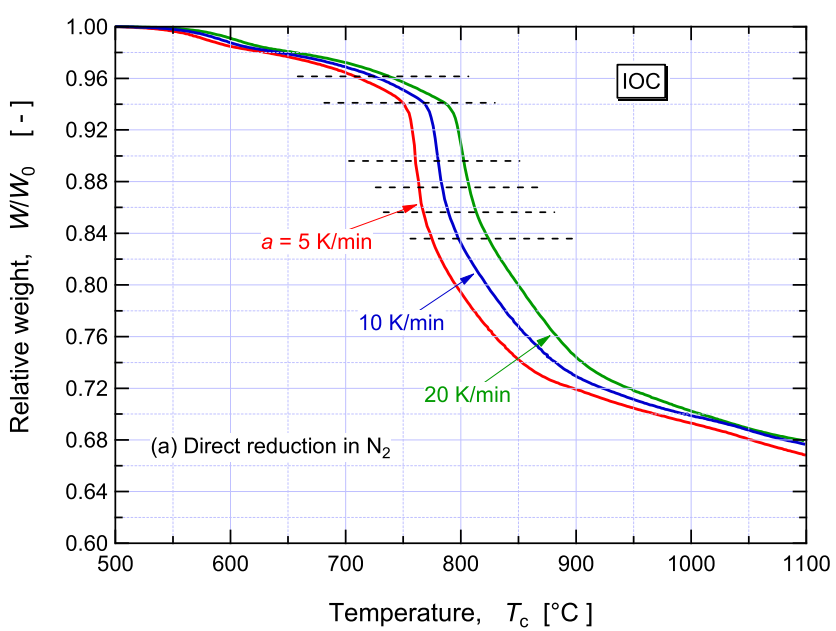

Fig. 15. Relationship between the relative weight, $W / W_{0}$, and temperature measured at three different heating rates for the direct reduction experiments of the IOC. (Online version in color.)

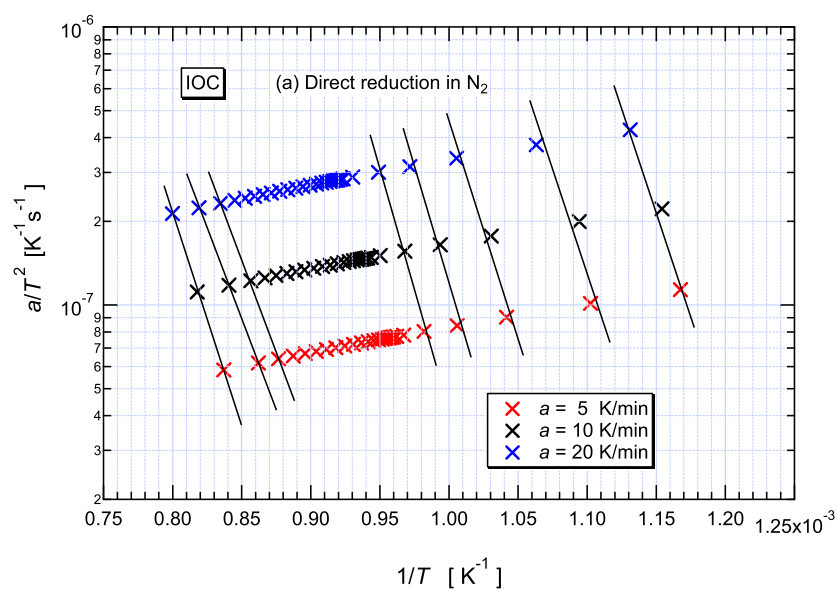

Fig. 16. The Arrhenius plots of $\ln \left(a / T^{2}\right)$ vs. $1 / T$ at same $W / W_{0}$ levels for the direct reduction experiments of the IOC. (Online version in color.)

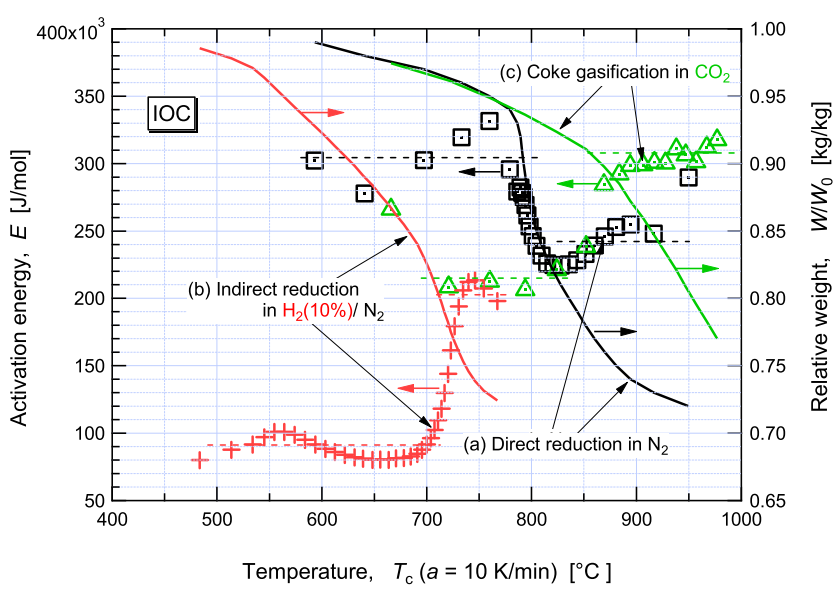

Fig. 17. Activation energies estimated for the three reaction systems. (Online version in color.) reduction as an example. The Arrhenius plots of $\ln \left(a / T^{2}\right)$ performed at several same $W / W_{0}$ levels are typically shown for (a) direct reduction in Fig. 16. By performing similar plots for both (b) indirect reduction and (c) coke gasification, changes of activation energies with temperature at $a=10 \mathrm{~K} / \mathrm{min}$ and $W / W_{0}$ are shown in Fig. 17 for the three reactions. It was judged that every reaction involves at least two reactions and every activation energy was estimated to be as follows:

(a) Direct reduction: $E_{1} \cong 310 \mathrm{~kJ} / \mathrm{mol}, E_{2} \cong 230-240 \mathrm{~kJ} /$ mol

(b) Indirect reduction: $E_{1} \cong 90 \mathrm{~kJ} / \mathrm{mol}, E_{2} \cong 200 \mathrm{~kJ} / \mathrm{mol}$

(c) Coke gasification: $E_{1} \cong 215 \mathrm{~kJ} / \mathrm{mol}, E_{2} \cong 310 \mathrm{~kJ} / \mathrm{mol}$ Judging from the range of $W / W_{0}$ values, the first and second reactions of (a) direct reduction are assumed to be respectively for Reaction (6) and Reaction (7), and the first and second reactions of (b) indirect reduction are assumed to be respectively for Reaction (10) and Reaction (11). Although it is very strange that $E_{1}$ is larger than $E_{2}$ for (a) direct reduction, we cannot explain the reason at the present. It is also interesting to note that two reactions are involved for (c) coke gasification. This may suggest that there exists two types of coke in the IOC. The rapid gasification of coke was judged to proceed by the redox cycle of $\mathrm{Fe}_{3} \mathrm{O}_{4}$ as shown by Reactions (6) and (21). ${ }^{15}$ ) The sum of these two reactions forms the gasification reaction (3). Since Reaction (6) is controlling the rate of gasification of coke, the activation energy of coke gasification should coincide with that of the direct reduction reaction (6). The activation energy of Reaction (6) is $\cong 310 \mathrm{~kJ} / \mathrm{mol}$ as discussed above, and the 2 nd activation energy of coke gasification is also $\cong 310 \mathrm{~kJ} /$ mol. This agreement suggests the soundness of the activation energies estimated.

$$
\underset{\mathrm{FeO}+\mathrm{CO}_{2} \rightarrow \mathrm{Fe}_{3} \mathrm{O}_{4}+\mathrm{CO} \text { (Rapid) } \ldots \ldots \ldots}{\mathrm{Fe}_{3} \mathrm{O}_{4}+\mathrm{C} \rightarrow 3 \mathrm{FeO}}+\mathrm{CO} \text { (Rate controlling) }
$$

As far as the authos know, little works have been performed to estimate the activation energies of both (a) direct rection and (b) indirect reduction. Takahashi et al. ${ }^{21)}$ reported in 1971 that the overall activation energy of the reduction of an iron oxide pellet by $\mathrm{H}_{2}$ was $26 \mathrm{kcal} / \mathrm{mol}$ (= $109 \mathrm{~kJ} / \mathrm{mol}$ ) in the temperature range of 1100 to $1400 \mathrm{~K}$. Although it may not be directly compared with the activation energies of this work, it is rather close to $E_{1}$ value of (b) in direct reduction.

\subsection{Formulation of Rate Equation for Coke Gasifica- tion}

Next, it was intended to estimate the fractional contributions $X_{10}$ and $X_{20}$ and to formulate the functions $f_{1}\left(X_{1}\right)$ and $f_{2}\left(X_{2}\right)$ for every reaction system. To do so, several reaction models given in Table 11 were tested. Models (a) to (c) are often used for the analysis of gas solid reactions, ${ }^{22)}$ and (d) Avrami model is well known to represent the change of $X$ flexibly and is applied to analyze nucleation reaction. ${ }^{23)}$ The values of $X_{\mathrm{i} 0}$ and $f_{\mathrm{i}}\left(X_{\mathrm{i}}\right)$ can be estimated by the following procedure. 
As stated above, Eq. (16) gives the relationship between $X$ and $k_{0} \tau_{\mathrm{a}}\left(=k_{0} e^{-E / R T} \frac{R T^{2}}{a E}\right)$ through $g(X)$ given in Table 11. Then the $X v s k_{0} \tau_{\mathrm{a}}$ diagrams, which we call mother diagrams, were constructed for all of the reaction models by taking $k_{0} \tau_{\mathrm{a}}$ axis logarithm scale as shown in Figs. 18(a) and 18(b). Then the following procedure is applied for single reactions with known $E$ values.

(1) Plot $X$ against $\tau_{\mathrm{a}}\left(=e^{-E / R T}\left(R T^{2} / a E\right)\right)$ taking the $\tau_{\mathrm{a}}$ axis logarithm scale on the same size of section paper at all the heating rates of three or more. The plots will coincide each other if the activation energy was correctly estimated. Let us call the plot $X-\tau_{\mathrm{a}}$ diagram.

(2) Superimpose the mother diagrams on the $X-\tau_{\mathrm{a}}$ diagram to find a most suitable $X v s . k_{0} e^{-E / R T}\left(R T^{2} / a E\right)$ relationship that fits the $X-\tau_{\mathrm{a}}$ diagram. The functional form $f(X)$ can be estimated from the superimposition.

(3) Comparing the abscissas of the mother diagram and the $X-\tau_{\mathrm{a}}$ diagram at the best superimposition, $k_{0}$ can be obtained.

For multiple reactions, the above procedure is applied for individual reactions constituting the multiple reactions. For (c) coke gasification, it was judged that the first reaction covers $0.68<1-X<0.9$ and the second stage covers $0<1-X<0.68$ by iterative trials. This means that $X_{10}=$ 0.32 and $X_{20}=0.68$. Then new conversions $X_{1}$ and $X_{2}$ can be calculated using the $1-X$ vs $T$ relationships and the $X_{10}$ and $X_{20}$ estimated. $X_{1}$ and $X_{2}$ were respectively plotted

Table 11. $f\left(x_{\mathrm{B}}\right)$ and $g\left(x_{\mathrm{B}}\right)$ for several reaction models.

\begin{tabular}{ccc}
\hline Reaction model & $f(X)$ & $g(X)$ \\
\hline $\begin{array}{c}\text { (a) Volume reaction } \\
\text { model (VR Model) } \\
\text { (b) Simple grain } \\
\text { model (Grain } \\
\text { Model-1) }\end{array}$ & $1-X$ & $-\ln (1-X)$ \\
(c) Random Pore & $(1-X)^{2 / 3}$ & $3\left\{1-(1-X)^{1 / 3}\right\}$ \\
$\begin{array}{c}\text { Model (RP Model) } \\
\text { (d) Avrami Erofe'ev } \\
\text { (Avrami Model) }\end{array}$ & $\alpha(1-X)[-\ln (1-X)]^{(\alpha-1) / \alpha}$ & {$[-\ln (1-X)]^{1 / \alpha}$} \\
\hline
\end{tabular}

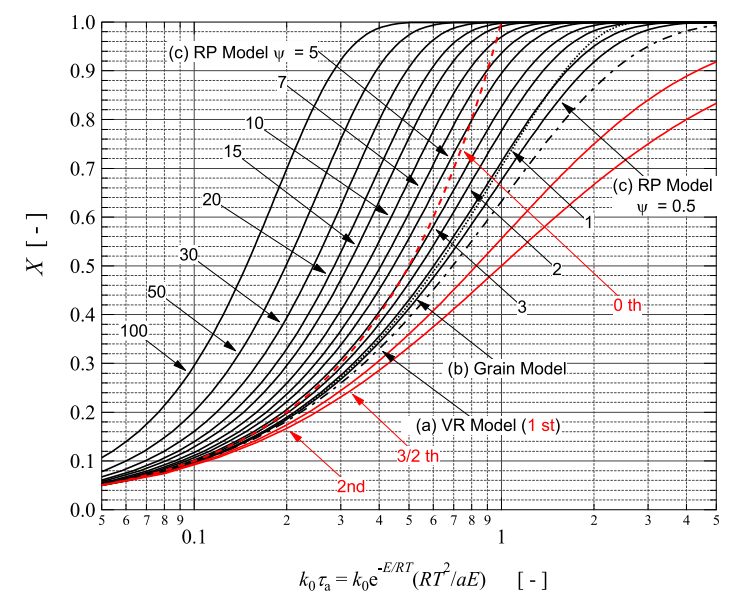

(a) against $\tau_{\mathrm{a} 1}\left(=e^{-E_{1} / R T}\left(R T^{2} / a E_{1}\right)\right)$ with $E_{1}=215 \mathrm{~kJ} / \mathrm{mol}$ and $\tau_{\mathrm{a} 2}\left(=e^{-E_{2} / R T}\left(R T^{2} / a E_{2}\right)\right)$ with $E_{2}=309 \mathrm{~kJ} / \mathrm{mol}$. Then the above procedure was applied for the two reactions to estimate $f_{1}\left(X_{1}\right), k_{01}, f_{2}\left(X_{2}\right)$, and $k_{02}$. Finally the rate equations for the two reactions were estimated as follows:

1st reaction:

$$
\begin{aligned}
& \mathrm{d} X_{1} / \mathrm{d} t=k_{01} e^{-E_{1} / R T}\left(1-X_{1}\right)^{3 / 2} \text { with } \\
& E_{1}=215 \mathrm{~kJ} / \mathrm{mol}, k_{01}=1.94 \times 10^{8} \mathrm{~s}^{-1}
\end{aligned} .
$$

2nd reaction:

$$
\begin{aligned}
& \mathrm{d} X_{2} / \mathrm{d} t=k_{02} e^{-E_{2} / R T}\left(1-X_{2}\right) \text { with } \\
& E_{2}=309 \mathrm{~kJ} / \mathrm{mol}, \quad k_{02}=7.14 \times 10^{10} \mathrm{~s}^{-1}
\end{aligned}
$$

Equations (22) and (23) are integrated to give respectively Eqs. (24) and (25).

$$
\begin{aligned}
1-X_{1} \cong 4 /\left(2+k_{01} e^{-E_{1} / R T} \cdot \frac{R T^{2}}{a E_{1}}\right)^{2} \\
1-X_{2} \cong \exp \left(-k_{02} e^{-E_{2} / R T} \cdot \frac{R T^{2}}{a E_{2}}\right) .
\end{aligned}
$$

Figure 19 compares the experimentally obtained $1-X v s$ $T$ relationships and the calculated ones using Eqs. (24) and (25). Good agreements between the experimental and calculated $1-X$ vs $T$ relationships for all heating rates suggest the validity of the rate equations obtained. The first reaction, however, was strangely represented by a 3/2-th order reaction which is rarely encountered in gas solid reactions. To analyze the first reaction, the mother curves for several n-th order reactions were constructed as shown by the red curves in Fig. 18(a). The activation energy of the 1 st reaction, $E_{1}$, was also much smaller than those reported on the $\mathrm{C}-\mathrm{CO}_{2}$ reaction. These results for the rate parameters with low reaction enthalpies obtained for the direct reduction and coke gasification suggests the uniqueness of coke in the IOC.

It was also intended to formulate rate equations for both

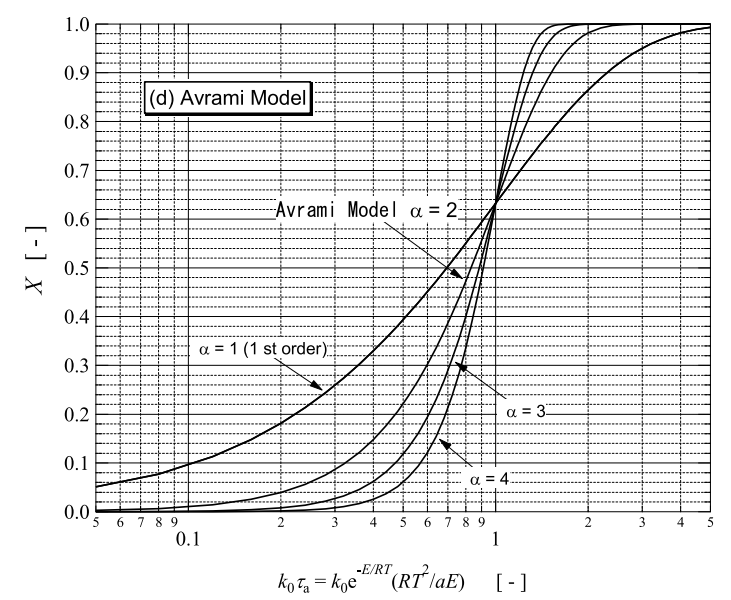

(b)

Fig. 18. Mother diagrams showing the relationships between $X$ and $k_{0} \tau_{\mathrm{a}}\left(=k_{0} e^{-E / R T} \frac{R T^{2}}{a E}\right)$. (Online version in color.) 


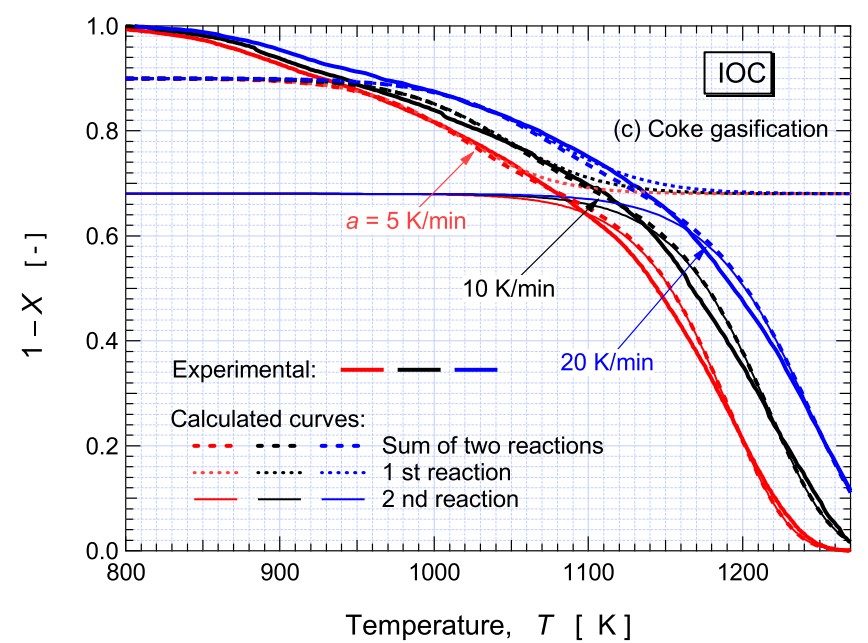

Fig. 19. Comparison between the experimentally obtained $1-X v s$ $T$ relationships and the calculated ones using Eqs. (24) and (25) for the coke gasification. (Online version in color.)

direct reduction and indirect reduction, but any models in Table 11 fitted the experimental data for the direct reduction. The experimentally obtained $X$ vs. $T$ relationships are too steep to fit the $X$ vs. $T$ relationships of the models due to large reduction rate. For the indirect reduction, it was difficult to find the dominant reaction at low temperature regions, which made it difficult to fit the experimental data to the models tested.

\section{Conclusion}

The reaction characteristics of a unique iron ore/carbon composite, IOC, prepared from Rove River and a coal tar vacuum residue, CTVR, were examined for its direct reduction, indirect reduction in a $\mathrm{H}_{2}$ atmosphere, and coke gasification in a $\mathrm{CO}_{2}$ atmosphere from the viewpoints of reaction enthalpies and rate parameters.

First, a methodology to estimate the reaction enthalpies using a TG-DSC analyzer was proposed using the decomposition of $\mathrm{CaCO}_{3}$ as a model reaction. For both the direct reduction and the coke gasification, the measured enthalpies were found to be less than half of the corresponding thermodynamic reaction enthalpies. For the indirect reduction, on the other hand, the measured reaction enthalpies at higher temperature region were almost same as those of the corresponding thermodynamic reaction enthalpies. For the indirect reduction of Robe River itself which was performed for comparison purpose, the measured reaction enthalpies over $400^{\circ} \mathrm{C}$ were almost exactly same as those of the corresponding thermodynamic reaction enthalpies.

The activation energies of the reactions were successfully estimated by Miura-Maki method. It was judged that every reaction involves at least two reactions and every activation energy was estimated to be as follows: direct reduction: $E_{1} \cong$ $310 \mathrm{~kJ} / \mathrm{mol}$ and $E_{2} \cong 230-240 \mathrm{~kJ} / \mathrm{mol}$, indirect reduction: $E_{1} \cong 90 \mathrm{~kJ} / \mathrm{mol}$ and $E_{2} \cong 200 \mathrm{~kJ} / \mathrm{mol}$, and coke gasification: $E_{1} \cong 215 \mathrm{~kJ} / \mathrm{mol}$ and $E_{2} \cong 310 \mathrm{~kJ} / \mathrm{mol}$. The rate equations were formulated for the two reactions involved in the coke gasification. The rapid 1st reaction was strangely represented by a 3/2-th order reaction against unreacted coke.

The examinations clarified that the coke retained intimately in the pore space of $\mathrm{Fe}_{2} \mathrm{O}_{3}$ are very reactive and show reaction characteristics different from bulk carbon.

\section{Acknowledgement}

This article is based on results obtained from "Development of technologies for environ-mentally harmonized steelmaking process, 'COURSE50"' project commissioned by the New Energy and Industrial Technology Development Organization (NEDO).

\section{REFERENCES}

1) Y. Matsui, M. Sawayama, A. Kasai, Y. Yamagata and F. Noma: ISIJ Int., 43 (2003), 1904.

2) S. K. Dey, B. Jana and A. Basumallick: ISIJ Int., 33 (1993), 735.

3) X. Zhang, R. Takahashi and J. Yagi: Testu-to-Hagané, 81 (1995), 1043 (in Japanese).

4) A. Kasai, M. Naito, Y. Matsui and Y. Yamagata: Tetsu-to-Hagané, 89 (2003), 1212 (in Japanese).

5) M. Nakano, M. Naito, K. Higuchi and K. Morimoto: ISIJ Int., 44 (2004), 2079.

6) Y. Iguchi and Y. Takada: ISIJ Int., 44 (2004), 673

7) Y. Iguchi and S. Yokomoto: ISIJ Int., 44 (2004), 2008.

8) E. Kasai, K. Mae and F. Saito: ISIJ Int., 35 (1995), 1444.

9) J. V. Khaki, Y. Kashiwaya, K. Ishii and H. Suzuki: ISIJ Int., 42 (2002), 13.

10) Y. Kashiwaya, H. Suzuki and K. Ishii: ISIJ Int., 44 (2004), 1970

11) Y. Kashiwaya, H. Suzuki and K. Ishii: ISIJ Int., 44 (2004), 1975.

12) Y. Kashiwaya, H. Suzuki and K. Ishii: ISIJ Int., 44 (2004), 1981.

13) N. Ishikawa, K. Furuya, N. Mitsuoka and T. Inami: ISIJ Int., 46 (2006), 1106.

14) M. Kawanari, A. Matsumoto, R. Ashida and K. Miura: ISIJ Int., 51 (2011), 1227.

15) K. Miura, K. Miyabayashi, M. Kawanari and R. Ashida: ISIJ Int., 51 (2011), 1234.

16) H. Naono and R. Fujiwara: J. Colloid Interface Sci., 73 (1980), 406.

17) R. Ashida, Y. Koeda and K. Miura: J. Chem. Eng. Jpn., 49 (2016), 300 .

18) C. D. Doyle: J. Appl. Polym. Sci., 5 (1961), 285.

19) T. Ozawa: Thermochim. Acta, 203 (1992), 159.

20) K. Miura and T. Maki: Energy Fuel., 12 (1998), 864.

21) R. Takahashi, J. Yagi and Y. Omori: Tetsu-to-Hagané, 57 (1971), No. 10, 1597 (in Japanese)

22) K. Miura and P. L. Silveston: Energy Fuel., 3 (1989), 243.

23) M. Avrami: J. Chem. Phys., 8 (1940), 212. 